\title{
Preventing Interpersonal Violence in Europe
}

\author{
Dinesh Sethi ${ }^{1}$, Dimitrinka Jordanova Peshevska ${ }^{2}$ \\ ${ }^{1}$ World Health Organization Regional Office for Europe, Copenhagen, Denmark; ${ }^{2}$ World Health Organization Country Office \\ Skopje, Skopje, Republic of Macedonia
}

\begin{abstract}
Citation: Sethi D, Jordanova Peshevska D. Preventing Interpersonal Violence in Europe. OA Maced J Med Sci. 2014 Jun 15; 2(2):350352. http://dx.doi.org/10.3889/oamjms.2014.060 Key words: violence; interpersonal violence prevalence; risk factors; Europe.

"Correspondence: Dr. Dinesh Sethi. World Health Organization, Regional Office for Europe Copenhagen, Denmark. E-Mail: DIN@euro.who.int

Received: 12-Jun-2014; Revised: 13-Jun2014; Accepted: 14-Jun-2014; Online first: 14-Jun-2014

Copyright: () 2014 Sethi \& Jordanova Peshevska. This is an open access article distributed under the terms of the Creative Commons Attribution License, which permits unrestricted use, distribution, and reproduction in any medium, provided the original author and source are credited.

Competing Interests: The authors have declared that no competing interests exist.
\end{abstract}

\begin{abstract}
AIM: To describe the burden of interpersonal violence, risk factors and discuss the need for evidence based action to reduce the public health threat of interpersonal violence.

METHODS: Global Health Estimates data were used to describe the mortality and meta-analyses from previous reports were used to describe the prevalence of the different types of interpersonal violence and to discuss the options for evidence informed prevention programmes.

RESULTS: In the 53 countries of the WHO European Region, violence kills about 160,000 people each year, and of these around 31,000 die from interpersonal violence, 123,000 from self-inflicted violence and 2,000 from war. Deaths are just the tip of the iceberg and for every death there are numerous admissions to hospital and emergency departments. Interpersonal violence is thought to be one of the most frequently experienced yet commonly overlooked forms of violence. Based upon data from meta-analyses of population surveys in Europe: the prevalence in children under 18 years of sexual abuse is $9.6 \%(13.4 \%$ in girls and $5.7 \%$ in boys); physical abuse is $22.9 \%$ and $29.1 \%$ for emotional abuse; the prevalence of intimate partner violence (physical and or sexual violence) is $19.3 \%$ in high-income countries and $25.6 \%$ in low- and middle-income countries, suggesting that about 49 million women aged 14-49 years have been abused. Surveys of older people over 60 years, suggest that the past year prevalence of physical abuse is $2.7 \%$, sexual abuse $0.7 \%$, emotional abuse $19 . \%$ and financial abuse $3.8 \%$, suggesting the numbers experiencing elder maltreatment in Europe run into the tens of millions
\end{abstract}

CONCLUSION: Community surveys can play an important role to better understand the scale and risk factors of different types of interpersonal violence. Readers are called upon to support a coordinated public health response to prevent this societal and health threat.
The World report on violence and health defines violence as the intentional use of physical force or power, threatened or actual, against oneself, another person, or against a group or community that results either in injury, death, psychological harm, maldevelopment or deprivation [1]. Violence may be self-directed (as in suicide or self-harm), interpersonal (child, partner, elder, acquaintance, stranger), and collective (such as in war and by gangs). In the 53 countries of the WHO European Region, violence kills about 160000 people each year, and of these around 31000 die from interpersonal violence, 123000 from self-inflicted violence and 2000 from war [2]. Deaths are just the tip of the iceberg and for every death there are numerous admissions to hospital and emergency departments. The clinical pyramid for all types of violence has not been properly estimated, but interpersonal violence is thought to result in at least one million injuries severe enough to warrant medical attention, resulting in high costs, competing for already over stretched resources [1]. The impact of nonfatal violence is thought to be enormous and has grave long-term physical, psychological, economic, social and developmental consequences for individuals and society. This is particularly true of some forms of violence such as child maltreatment, intimate partner violence and elder maltreatment, which are highly prevalent, and often nonfatal, but have far reaching health and social consequences. These types of violence often occur in the home and remain hidden because they are rarely reported to the authorities. Population surveys are therefore an essential supplement to detecting the scale, understanding the risk and protective factors for interpersonal violence and for monitoring and evaluating the response to programmes.

Interpersonal violence is thought to be one of 
the most frequently experienced yet commonly overlooked forms of violence. Based upon data from meta-analyses of population surveys in Europe, the prevalence in children under 18 years of sexual abuse is $9.6 \%(13.4 \%$ in girls and $5.7 \%$ in boys), physical abuse is $22.9 \%$ and $29.1 \%$ for emotional abuse. This suggests that an estimated 18 million children are affected by sexual abuse, 44 million by physical abuse and 55 million by emotional abuse [3]. The WHO multi-country study on domestic violence interviewed 24000 women in urban and rural settings in 10 countries, and showed that the proportion of women reporting having ever experienced sexual and/or physical violence at the hands of an intimate partner ranged from $15 \%$ to $71 \%$ [4]. A meta-analysis conducted more recently shows that in the European region, the prevalence of intimate partner violence (physical and or sexual violence) is $19.3 \%$ in highincome countries and $25.6 \%$ in low- and middleincome countries, suggesting that about 49 million women aged 14-49 years have been abused [5]. Surveys of older people over 60 years, suggest that the past year prevalence of physical abuse is $2.7 \%$, sexual abuse $0.7 \%$, emotional abuse $19 . \%$ and financial abuse $3.8 \%$, suggesting the numbers experiencing elder maltreatment in Europe run into the tens of millions [6]. Furthermore child abuse may co-occur in $40 \%$ of families with domestic violence and witnessing parental violence is harmful to a child's development and considered an adverse childhood experience. Numerous surveys of adverse childhood experiences surveys have shown that the prevalence of child maltreatment is high, as is household dysfunction (living in a household where there in parental violence, separation or divorce, where a household member has a mental illness, alcohol or drug problem or has been incarcerated), and these have shown a strong association with developing health harming behaviours such as smoking, physical inactivity, alcohol or drug misuse, self-harm, riskysexual behaviour, and being a victim or perpetrator of violence, which in turn affect physical, mental and social well-being $[3,7]$.

Although all types of interpersonal violence happen in all societies, their occurrence is far from random. In Europe $74 \%$ of all homicides occur in males. Males aged $15-49$ years are at many times greater risk of being involved - as victims and as perpetrators in both fatal and non-fatal violence. Females are at substantially higher risk than males of being victims of sexual violence and of serious physical assault in intimate partner violence. Homicide rates are strongly correlated with economic inequality, the highest rates occurring in the poorest communities of societies with the biggest gaps between the rich and the poor. For example the homicide rates in lowand middle-income countries are 7.4 times higher than in high-income countries of the region [2]. Within countries fatal and non-fatal assault rates in adolescents and youth are several times higher than in more socio-economically deprived groups compared to the more affluent [8]. There is compelling evidence that interpersonal violence is partly driven by socioeconomic determinants and that it is a leading cause of inequity and social injustice.

There are a number of risk factors that are common to the different types of violence. These include weak legislation to protect against violence, socio-economic inequality, poor social capital, norms that support violence, gender inequalities, freer access to alcohol, availability of firearms, availability of drugs, familial strife, previous history of being abused, low educational attainment and single parenthood coupled with economic stress and other factors such as those comprising household dysfunction. The evidence base of what can be done about preventing interpersonal violence is growing. There is also an increasing awareness of the intergenerational transmission of violence and how prevention efforts need to start early in childhood and be based on a life-course approach [1, 3, 6-8]. Child maltreatment prevention programmes include home visiting, positive parenting programmes, multicomponent programmes, social marketing to change social norms, reducing the availability of alcohol, providing welfare support to at risk families, hospital based programmes to prevent abusive head trauma and laws that ban the use of corporal punishment $[1,3,7]$. It is argued that investment in these will reduce not only child maltreatment, but will also have beneficial effects on the different types of interpersonal violence and across the generations.

Worldwide, violence results in large expenditures not only for health care and social and economic development and support foregone, but also for other sectors, such as law enforcement, and compensating survivors for their suffering. It diverts many billions of Euros from more constructive investments. The fear of such violence provokes personal and societal reactions that further widen the gaps between the rich and the poor. There are enormous indirect costs, too, with large societal losses which can result in slower economic development, socioeconomic inequality, and an erosion of human and social capital [1].

International policy initiatives such as the World Health Assembly resolution on violence prevention and the UN Convention of the Rights of the Child have been catalysts for policy action. To ensure a wider implementation also requires an explicit recognition by policy-makers that violence is a preventable public health problem. Resources need to be mobilized in order to build capacity and implement and evaluate interventions on a broader scale across all the sectors. Policies which safeguard children, youth, women and elders from violence need to be integrated and prioritized into across the broad range of social policy whether this is education, health, social welfare, economic and law enforcement policies, requiring a coordinated multisectoral response [9]. One of the challenges facing society is 
mobilizing the political support needed to tackle the current norms of violence, poverty and alcohol consumption which perpetuate interpersonal violence in all its pervasive forms [10]. The new European health policy, Health 2020 urges the health sector to work with other sectors emphasising the life course approach to achieve better equity in health through evidence informed prevention [11]. Violence prevention programmes underpin these crucial principles.

Whatever its form, interpersonal violence kills, maims and otherwise destroys the health and wellbeing of tens of millions of people each year. It is therefore particularly relevant that this Journal has undertaken a series of publications to highlight the role that surveys can play to better understand the scale of the problem of interpersonal violence. We call on the readers to mount a concerted public health response to prevent the health and societal threat.

\section{References}

1. Krug E, Dahlberg LL, Mercy JA, Zwi AB. World report on violence and health. Geneva: World Health Organization, 2002.

2. World Health Organization. Global health estimates - Disease and injury regional estimates 2000-2011 [on line data base]. Geneva: World Health Organization, 2013. http://www.who.int/healthinfo/global_burden_disease/en/ (Accessed 12 April 2014)

3. Sethi D, Bellis $M$, Hughes $K$, et al. European report on preventing child maltreatment. Copenhagen: World Health Organization Regional Office for Europe, 2013.

4. Garcia-Moreno C, Jansen HAFM, Ellsbeg M, Heise L, Watts C WHO Multi-country study on women's health and domestic violence against women. Initial responses on prevalence, health outcomes and women's responses. Geneva: World Health Organization, 2005.

5. Global and regional estimates of violence against women: prevalence and health effects of intimate partner violence and non-partner sexual violence. Geneva: World Health Organization, 2013.

6. Sethi D, Wood S, Mitis F, et al. European report on preventing elder maltreatment. Copenhagen: World Health Organization Regional Office for Europe, 2011.

7. Butchart A, Harvey AP, Mian M, Furniss T. Preventing child maltreatment: a guide to taking action and generating evidence. Geneva: World Health Organization, 2006.

8. Sethi D, Hughes $\mathrm{K}$, Bellis $\mathrm{M}$, et al. European report on preventing violence and knife crime among young people. Copenhagen: World Health Organization Regional Office for Europe, 2010.

9. World Health Organization. Preventing injuries and violence: a guide for ministries of health. Geneva: World Health Organization, 2007.

10. Jewkes R. Intimate partner violence: causes and prevention. Lancet 2002; 359:1423-29.

11. Health 2020: the European policy for health and well-being Copenhagen: World Health Organization Regional Office for Europe, 2012. 